\title{
A GIS database documenting the historical geography of south-central Transylvania in the Modern Age (1699-1867)
}

\author{
Andrei $\mathrm{Nacu}^{\mathrm{a}, *}$ \\ ${ }^{a}$ Romanian Academy, Institute of Social Sciences and Humanities Sibiu, Bulevardul Victoriei 40, Sibiu, 550024, Romania, \\ andreinacu1@yahoo.com;nacu@icsusib.com
}

Keywords: Historical GIS, cartographic heritage, georeferencing, vectorization

\begin{abstract}
:
The central part of southern Transylvania is a distinct region of Romania, featuring a rich cultural heritage and a unique multi-ethnic charm. The territory has roughly $15,000 \mathrm{~km}^{2}$ and was permanently transformed after the colonization of a German-speaking population (the Transylvania Saxons) by the kings of Hungary in the 12th and 13th centuries.

The study presents the steps taken to create a Historical GIS (HGIS) database dedicated to this area. While the methodology employed is not novel, a comparable undertaking was seldom completed before for a historical region in Romania.

The research period is placed between 1699, the year of the Treaty of Karlowitz and the official annexation of the Principality of Transylvania to the Habsburg dominions, and 1867, the year when the Austro-Hungarian Compromise (Ausgleich) was concluded.

Regional maps of Transylvania have been produced since the 16th century, but in the 18th and 19th centuries, the Austrian military engineers and general staff officers have conducted topographic surveys and have meticulously mapped all the major cities in the province. Furthermore, the founding of a lithographic institute in Sibiu in 1822 stimulated the local development of commercial cartography.

The geographical features included in the HGIS database were vectorized chiefly from three maps of the province, created in 1751, 1769-1773 and 1853-1870, respectively. Apart from the maps of Transylvania, we have also processed city plans depicting the five major urban settlements in the investigated region (Sibiu, Brașov, Mediaș, Sighișoara and Sebeș). Most of the selected cartographic documents, both city plans and regional maps, are held in Austrian and Hungarian archives and libraries, specifically the War Archive (Kriegsarchiv) of the Austrian National Archives in Vienna, the Austrian National Library and the Military Institute and Museum in Budapest. Several plans of Sibiu, Brașov and Mediaș are kept in local archives and libraries in Romania (the Sibiu and Braşov County Directions of the Romanian National Archives and the Library of the Brukenthal National Museum in Sibiu).
\end{abstract}

The scanned copies of the cartographic documents were georeferenced and the essential contents were vectorized and categorized accordingly (forests, built-up areas, roads, fortifications, churches, post stations etc.). Additionally, the corresponding labels, as well as the street and place names, were recorded in the attribute table. The vector files were then grouped in two main data packages, each of them reflecting the historical geography at two points in time, in the 18 th century (ca. 1750-1773) and in the 19th century (ca. 1850-1870).

The HGIS database represents a valuable working tool for prospective studies regarding the historical landscape of southern Transylvania. The database will be published online, on a dedicated website, and some of the vector files will be made available under a Creative Commons license, allowing the use of the GIS data in a wide range of domains: geography, history, archaeology, urban planning, architecture, sociology and linguistics. 